\title{
BLOOD PRESSURE PROFILE OF SCHOOL CHILDREN OF GULBARGA CITY
}

Mujumdar. V.G, Amruta Swati Indupalli, Siddaling Changty, Ayesha Batool, Fatima

1. Assistant Professor, Department of Paediatrics, Khaja Banda Nawaz Institution of Medical Sciences, Roza B. Gulbarga.

2. Associate Professor, Department of Community Medicine, Khaja Banda Nawaz Institution of Medical Sciences, Roza - B. Gulbarga.

3. Associate Professor, Department of Paediatrics, Khaja Banda Nawaz Institution of Medical Sciences, Roza B. Gulbarga.

4. Junior Resident, Department of Paediatrics, Khaja Banda Nawaz Institution of Medical Sciences, Roza - B. Gulbarga.

5. Junior Resident, Department of Paediatrics, Khaja Banda Nawaz Institution of Medical Sciences, Roza - B. Gulbarga.

\section{CORRESPONDING ADDRESS:}

Dr. Mujumdar. V.G

Plot \#34, N. G. O. S

Housing Colony. Jewargi Road

Gulbarga.

E-Mail: drmujumdarvg@gmail.com,

Phone: 00919448978170.

ABSTRACT: BACKGROUND: High blood pressure in childhood is a major risk factor for heart disease and stroke in adulthood. There is enough evidence to suggest that the roots of essential hypertension in adults extend into childhood. There is a paucity of literature on the blood pressure measurements amongst children. This study was done to study blood pressure profile of school children in Gulbarga, Karnataka, India. AIM \& OBJECTIVES: To determine the prevalence of hypertension in children 6-15 years of age and to study the association between selected variables and blood pressure. MATERIAL \& METHODS: The present study was a school based cross sectional study conducted in 2 Government Primary Schools and 2 Private Secondary Schools of Gulbarga city. For the study 1320 children in the age group 6-15 years were selected. Sample size of 347 was calculated by, using the formula for sample size calculation for single population proportion from a Study where the prevalence of hypertension was $2.42 \%$.The data was collected in a Pre designed pre tested Performa and analyzed using appropriate statistical tests. RESULTS: The prevalence of hypertension in the study was found to be $2.42 \%$ with $2.4 \%$ in females and $2.3 \%$ in males. CONCLUSION: In the study, hypertension in students was found to be significantly associated with age, height and weight. There was no significant difference in blood pressures of the two sexes, when the values are corrected for maturation status; it was found that body weight and height are the principle determinants of blood pressure. With the onset of puberty spurt in systolic blood pressure was observed in both sexes equally.

KEY WORDS: school children; blood pressure; prevalence

INTRODUCTION: Prevalence of high blood pressure is now commonly observed in children with estimated population prevalence of $1-2 \%$ in the developed countries. ${ }^{1}$ Hypertension is known to be a major cause of morbidity and mortality in many countries, and the long-term 
health risks to children with hypertension may be substantial. However, Idiopathic or essential hypertension, for which no identifiable cause is found, clearly can begin in childhood. If untreated, over time high blood pressure can damage many organs of the body, including the heart, brain, kidneys and eyes. ${ }^{2}$

Many challenges remain in the study of pediatric hypertension. It is known that children who have high blood pressure tend to be hypertensive as adults. It remains to be definitively determined what level of blood pressure predicts hypertensive end-organ injury. The effects of hypertension can begin during childhood. The high blood pressure itself usually has no signs or symptoms, but may be associated with subtle changes in behavior or school performance. You can have it for years without knowing it. During this time, though High blood pressure can damage your heart, blood vessels, kidneys, and other parts of your body. The causes for increase in blood pressure are attributed to obesity, change in dietary habits, decreased physical activity and increasing stress. Elevated blood pressure, systolic or diastolic at any age, in either sex is a contributor for all forms of cardiovascular diseases. Early child hood identifying and modifying risk factors reduces the incidence and complications in adolescents and adults. Prevalence of hypertension varies across countries and states. It is multifactorial disease, influenced by genetic, racial, geographic, cultural and dietary patterns. There is enough evidence to suggest that the roots of essential hypertension in adults extend into childhood. The American Heart Association recommends that, all the children aged 3 years and older should have yearly blood pressure measurements. There is a paucity of literature on the blood pressure measurements amongst children. This study was done to know the blood pressure profile of school children in Gulbarga, Karnataka, India.

OBJECTIVE: To know the prevalence of hypertension in children 6-15 years

and

To study the association between selected variables and blood pressure.

MATERIALS AND METHODS: The present study was a school based cross sectional study conducted in 2 Government Primary Schools and 2Private Secondary Schools of Gulbarga city. For the study 1320 children of in the age group 6-15 years were selected. Sample size of 347 was calculated using the formula for sample size calculation for single population proportion from a Study, $\underline{3}$ where the prevalence of hypertension was $2.42 \%$. Any child with a known medical conditions having direct effect on blood pressure was excluded. One child with Mar fan's syndrome having mitral valve prolapse, was excluded.

DEFINITIONS ${ }^{3}$ : The classification of BP percentiles for this study was determined using normative tables generated from the New data, from the 1999-2000 National Health and Nutrition Examination Survey (NHANES) data submitted by National High Blood Pressure Education Program Working Group on Hypertension Education in Children and Adolescents, which take into account the age, gender and height of each child

Hypertension is defined as a average Systolic Blood pressure (SBP) and or Diastolic Blood pressure (DBP), that is $>95^{\text {th }}$ percentile for gender, age, and height on three or more occasions.

Pre-hypertension in children is defined as average SBP or DBP levels that are $>90^{\text {th }}$ percentile but $<95^{\text {th }}$ percentile. 
Normal BP is defined as a SBP and DBP that is less than the $90^{\text {th }}$ percentile for sex, age, and height. Revised Blood pressure tables were used to determine the percentiles.

A preformed questionnaire was designed and pre-tested on 44 students (excluded from study) on a school in the nearby and validated during pilot study. This study was done using predesigned questionnaire, by interview techniques, followed by measurements of height and weight, Age was recorded as per school records, Blood pressure was measured by using standardized mercury sphygmomanometer, as per standard guidelines with an appropriately sized cuff on three different occasions. The systolic blood pressure was determined by the onset of the "tapping" Korotkoff-1 sound and the diastolic at its disappearance (Korotkoff-5). Students found to have pre-hypertension (SBP or DBP $>90^{\text {th }}$ percentile) or hypertension (SBP or DBP $>95^{\text {th }}$ percentile) on first visit were re-examined on at least three different occasions to conclude the presence or absence of hypertension.

The English questionnaire was translated to Kannada. The data was collected and analyzed using appropriate statistical tests. The mean systolic and mean diastolic blood pressures with the standard deviations, for each age, sex, and various percentiles were determined. Similarly mean systolic and mean diastolic blood pressure with standard deviation were determined in different weight and height groups.

The physical instruments used in the study were a weighing machine, portable anthropometric rod and mercury sphygmomanometer with different cuff sizes. Calibration of the instruments was carried out. Different cuff sizes as recommended by the 2004 update of American Academy of Pediatrics on Hypertension $\underline{6}$ were used.

RESULTS: One thousand three hundred and twenty, apparently normal school children, between 6-15 years of age were studied to define norms of ascultatory blood pressure. Out of 781 were boys and 539 were girls. The mean systolic blood pressure for boys and girls was $104.78 \pm 9.24$ and $104.55 \pm 8.84$ respectively and mean diastolic blood pressure was 66.72 \pm 6.66 for boys and $66.69 \pm 6.15$ for girls and 320 (24.24\%) children had family history of hypertension.

Table 1 shows the comparative values of mean blood pressure for boys and girls. Systolic BP ranged from $68 \mathrm{mmHg}$ to $132 \mathrm{mmHg}$ in boys and $90-128 \mathrm{mmHg}$ in girls. The mean systolic Blood pressure in the age group of 6 to 15years ranged from $96.12 \mathrm{mmHg}$ to114.77 $\mathrm{mmHg}$ in boys and $95.4 \mathrm{mmHg}$ to $113.29 \mathrm{mmHg}$ in girls. A spurt in mean systolic blood pressure was observed between 13-14years and 14-15years of age.

Diastolic BP ranged from 50 to $96 \mathrm{mmHg}$ in boys and $50-84 \mathrm{mmHg}$ in girls. where as the mean Diastolic Blood Pressure ranged from $62.22 \mathrm{mmHg}$ to $73.59 \mathrm{mmHg}$ and $62.49 \mathrm{mmHg}$ to $72.87 \mathrm{~mm} \mathrm{Hg}$ for 6to 15 years of age in boys and girls respectively.

Table 2 reveled in boys mean systolic blood pressure with respect to weight ranged from $96.84 \mathrm{~mm}$ of $\mathrm{Hg}(10-15 \mathrm{~kg}$ group) to $116.81 \mathrm{~mm} \mathrm{Hg}(46-50 \mathrm{~kg}$ group), where as mean diastolic blood pressure ranged from $63.29 \mathrm{~mm}$ of $\mathrm{Hg}$ to $74.63 \mathrm{~mm} \mathrm{Hg}$. In girls, mean systolic blood pressure with respect to weight ranged from $97.62 \mathrm{~mm} \mathrm{Hg}$ (10 to $15 \mathrm{~kg}$ group) to $117.60 \mathrm{~mm} \mathrm{Hg}$ (46-50 $\mathrm{kg}$ group) where as mean diastolic blood pressure ranged from $64.28 \mathrm{~mm} \mathrm{Hg}$ to $76.40 \mathrm{~mm} \mathrm{Hg}$.

Table 3 Indicates boys with respect to height mean systolic blood pressure ranged from $96.12 \mathrm{~mm} \mathrm{Hg}$ (91to100 cm group) to $118.28 \mathrm{~mm} \mathrm{Hg}$ (161to $170 \mathrm{cms}$ group) where as mean diastolic blood pressure ranged from $61.86 \mathrm{~mm}$ of $\mathrm{Hg}$ to $76.00 \mathrm{~mm} \mathrm{Hg}$. In girls with respect to height, mean systolic blood pressure ranged from $96.57 \mathrm{~mm} \mathrm{Hg}$ (91to $100 \mathrm{cms}$ group) 
to120.26mm $\mathrm{Hg}$ (161to170 $\mathrm{cm}$ group), whereas mean diastolic blood pressure ranged from62.57 to $77.60 \mathrm{~mm} \mathrm{Hg}$.

The mean systolic and mean diastolic pressure were found to increase with increasing age, the increase in the mean systolic blood pressure being approximately 1.5 to $2 \mathrm{~mm} \mathrm{Hg}$ per year. The increase in mean diastolic was approximately $1 \mathrm{~mm} \mathrm{Hg}$ per year. Both systolic and diastolic blood pressure were found to have significant correlation with weight and height and hence with weight/height ratio in both sexes.

The mean systolic blood pressures and diastolic blood pressures in boys and girls were compared. It was found that the systolic and diastolic blood pressures were slightly higher in boys than in girls. However the difference was not statically significant.

Table 4 reveal the overall prevalence of hypertension in the present study was $2.42 \%$ (32). Of these 32 hypertensive childern 18 were boys amounting to $2.3 \%$ of total number of boys and 14 were girls amounting to $2.4 \%$ of total number of girls. The prevalence of hypertension was more in the 9 year old boys where as it was in 14 year old girls. All the 32 children had only mildly elevated blood pressure levels (i.e $>95^{\text {th }}$ percentile but $<99^{\text {th }}$ percentile).

DISCUSSION: The finding of the present study regarding mean systolic and mean diastolic blood pressure are comparable with findings of the study conducted by N.K. Anand and Lalit Tandon. ${ }^{4}$ Their findings (systolic blood pressure) of $96.3 \mathrm{~mm} \mathrm{Hg}$ at 6 years and $116.5 \mathrm{~mm} \mathrm{Hg}$ at15 years for boys and $95 \mathrm{mmHg}$ and $116.4 \mathrm{mmHg}$ at15 years for girls are close to the findings of the present study. Similarly diastolic blood pressure for both boys and girls in the present study and the study conducted by N. K. Anand Lalit Tandon are comparable. 4

The systolic spurt observed in the present study between 13-14 years in both sexes has been supported by Agarwal Rajiv, Sharma, AK Shrivastava, Premkumar and CM Pandey who observed similar spurts in systolic blood pressure in both sexes between 12 and 13 years of age. ${ }^{5}$ Raksh Agarwal, SL Mandowara, B Bhandri and Garg OP also observed a spurt in blood pressure between 12 and 13 years. ${ }^{6}$ The steep rise in systolic blood pressure was also observed by Londe between 5 to 6 years in boys, 4 to 5 years in girls and between 14 to 15 years in both sexes. $^{7}$

However, Task Force Committee USA reported only once spurt between 5 and 6 years in both sexes. The gradual increase in the blood pressure along with increase in age can be explained by the fact that, the body mass also increases, which is one of the determinants of blood pressure along with age. ${ }^{8}$

The systolic spurts observed in the present study can be accounted by the onset of puberty in both sexes, which results in increase of body weight and height, as a result of increase in muscular tissue in boys and deposition of adipose tissue in girls which begins around 11 to 12 years and reaches peak levels by 14-15 year of age.

The observations of mean diastolic pressure in the present study resemble those of the study conducted by $\mathrm{N} \mathrm{K}$ Anand and Lalit Tondon. ${ }^{4}$ In the present studies it range from 61.88 $\mathrm{mm} \mathrm{Hg}$ at 6 years to $73.9 \mathrm{~mm} \mathrm{Hg}$ at 15 years in boys where as from $62.09 \mathrm{~mm} \mathrm{Hg}$ at 6 years to $72.8 \mathrm{~mm} \mathrm{Hg}$ at 15 years in girls.

In the study conducted by $\mathrm{N} \mathrm{K}$ Anand and Lalit Tondon it ranged from $64.4 \mathrm{~mm} \mathrm{Hg}$ at 6 years and $76.9 \mathrm{~mm} \mathrm{Hg}$ at 15 years in boys and $64.3 \mathrm{~mm} \mathrm{Hg}$ at 6 years and $76.3 \mathrm{~mm} \mathrm{Hg}$ at 15 years in girls. ${ }^{4}$ Rakesh Agarwal, SL Mandowara, B Bhandari and Garg OP reported a diastolic blood pressure range of 65 to $77 \mathrm{~mm} \mathrm{Hg}$ for boys and $67.78 \mathrm{~mm} \mathrm{Hg}$ for girls in 5-15 years of age group. ${ }^{6}$ 
All above studies including present study shown approximate increase of diastolic pressure $1 \mathrm{~mm}$ Hg per year of age. There is a spurt of diastolic blood pressure in 13-14 years of age group in females in the present studies.

The findings of the present study are in agreement with the statement that height and weight are the strongest determinants of the blood pressure.

It can be seen from the results of the present study, that there were very little differences in the mean systolic blood pressure and mean diastolic blood pressure in all age groups, in between girls and boys.

In the present study the overall prevalence of hypertension as found to be $2.42 \%, 2.3 \%$ of total number of boys and $2.4 \%$ of total number of girls. Findings of current study were in the range of the study conducted by Sukumar 2\% Londe 2.3\% and R Agarwal 2.6\%.9,7,6

CONCLUSION: The overall prevalence of hypertension in the present study was $2.42 \%$.

of these 32 children, 18 were boys amounting to $2.3 \%$ of total number of boys and 14 were girls amounting to $2.4 \%$ of total number of girls. The findings of the present study are in agreement with the statement that the blood pressure, both systolic and diastolic gradually increases with age, although such an increase is not a steady one. It can be seen from the results of the present study that there were very little differences in systolic blood pressure and diastolic blood pressure in all groups in between girls and boys. The findings of the present study are in agreement with the statement that height and weight are the strongest determinants of the blood pressure.

RECOMMENDATIONS: Blood pressure recording should be a part of school health program and also of clinical examination of children, attending health care system, to identify and treat hypertension early to prevent the late complications.

\section{REFERENCES:}

1. Nirav Buch, Jagdish P. Goyal, Nagendra Kumar, Indira Parmar, Vijay B. Shah, and Jaykaran Charan, Prevalence of hypertension in school going children of Surat city, Western India. J Cardiovasc Dis Res. 2011 Oct-Dec; 2(4): 228-232.

2. http://www.pediatrichypertension.org/home.asp Accessed on 07.11.12.

3. The Fourth Report on the diagnosis, evaluation, and treatment of high blood pressure in children and adolescents. Pediatrics. 2004;114:555-576.

4. Anand NK andLalit Tandon, Prevalence of hypertension in school going children,Indian journal of paediatrics, 1996, 33,377-381.

5. Agarwal VK, Sharan R, Srivastava AK, Kumar P, Pandey CM, Blood pressure profile in children of age 3-15 years. Indian Pediatr 1983:20:921-5.

6. Agarwal R, Mandowara SL, Bhandari B,Garg OP, Prevalence of hypertension in apparently healthy school children, Indian Paediatrics,1982;19;779-784.

7. Londe S, Bourgoigine JJ, and Robson AM. "Hypertension in apparently normal children" Journal of Pediatrics 1971:78: 569-577.

8. Report of the Second Task Force Committee on Blood Pressure Control in Children. Pediatrics 1987, 79: 1-25.

9. Sukumar IP, Alurkar VM. Systemic high arterial pressure in children. Indian Heart Journal 1978, 30: 69. 
Table 1 Age wise comparison of mean blood pressure between boys and girls.

\begin{tabular}{|l|l|l|l|l|}
\hline \multirow{3}{*}{$\begin{array}{l}\text { Age } \\
\text { years }\end{array}$} & \multicolumn{3}{|l|}{ Systolic Blood Pressure } & \multicolumn{2}{l|}{ Diastolic Blood Pressure } \\
\cline { 2 - 5 } & $\begin{array}{l}\text { Boys } \\
\text { Mean } \pm \text { SD } \\
\text { mmHg }\end{array}$ & $\begin{array}{l}\text { Girls } \\
\text { Mean } \pm \text { SD } \\
\text { mmHg }\end{array}$ & $\begin{array}{l}\text { Boys } \\
\text { Mean } \pm \text { SD } \\
\text { mmHg }\end{array}$ & $\begin{array}{l}\text { Girls } \\
\text { Mean } \pm S D \\
\text { mmHg }\end{array}$ \\
\hline 6 & $96.12 \pm 5.13$ & $94.41 \pm 5.31$ & $62.22 \pm 4.49$ & $62.49 \pm 4.31$ \\
\hline 7 & $98.22 \pm 6.86$ & $98.67 \pm 7.55$ & $62.58 \pm 4.14$ & $62.40 \pm 5.43$ \\
\hline 8 & $102.15 \pm 7.43$ & $99.55 \pm 7.55$ & $63.35 \pm 6.92$ & $62.75 \pm 6.89$ \\
\hline 9 & $103.62 \pm 8.87$ & $102.23 \pm 6.92$ & $65.35 \pm 7.05$ & $63.71 \pm 4.73$ \\
\hline 10 & $104.41 \pm 7.91$ & $104.65 \pm 7.60$ & $66.30 \pm 5.81$ & $66.51 \pm 6.79$ \\
\hline 11 & $105.08 \pm 8.23$ & $105.24 \pm 7.95$ & $68.02 \pm 6.78$ & $66.88 \pm 4.42$ \\
\hline 12 & $106.24 \pm 8.14$ & $107.85 \pm 7.05$ & $68.60 \pm 5.29$ & $67.28 \pm 3.12$ \\
\hline 13 & $108.45 \pm 7.20$ & $108.22 \pm 10.80$ & $69.06 \pm 4.86$ & $68.71 \pm 5.57$ \\
\hline 14 & $111.64 \pm 7.18$ & $110.56 \pm 6.39$ & $70.89 \pm 4.96$ & $71.78 \pm 3.37$ \\
\hline 15 & $114.77 \pm 5.29$ & $113.29 \pm 6.67$ & $73.59 \pm 4.96$ & $72.87 \pm 4.40$ \\
\hline \hline
\end{tabular}

Table 2: Showing the distribution of boys and girls according to weight and Blood Pressure.

\begin{tabular}{|c|c|c|c|c|c|c|c|c|c|c|}
\hline \multirow{3}{*}{$\begin{array}{l}\text { Weight } \\
\text { (Kgs) }\end{array}$} & \multicolumn{5}{|c|}{ Boys } & \multicolumn{5}{|c|}{ Girls } \\
\hline & \multirow[t]{2}{*}{ No: } & \multicolumn{2}{|c|}{ SBP (mmHg) } & \multicolumn{2}{|c|}{ DBP (mmHg) } & \multirow[t]{2}{*}{ No: } & \multicolumn{2}{|c|}{ SBP (mmHg) } & \multicolumn{2}{|c|}{ DBP (mmHg) } \\
\hline & & Mean & SD & Mean & SD & & Mean & SD & Mean & SD \\
\hline $10-15$ & 82 & 96.84 & 7.25 & 63.29 & 5.99 & 70 & 97.62 & 8.25 & 64.28 & 6.34 \\
\hline $16-20$ & 266 & 99.30 & 7.32 & 63.58 & 5.10 & 169 & 100.53 & 7.12 & 64.90 & 5.27 \\
\hline $21-25$ & 173 & 104.90 & 8.10 & 66.64 & 6.52 & 65 & 105.89 & 7.96 & 66.90 & 5.73 \\
\hline $26-30$ & 123 & 108.32 & 7.81 & 69.86 & 5.77 & 150 & 110.28 & 8.20 & 70.86 & 4.61 \\
\hline $31-35$ & 53 & 110.67 & 7.81 & 71.20 & 5.83 & 37 & 111.62 & 11.80 & 72.21 & 3.90 \\
\hline $36-40$ & 48 & 113.04 & 6.11 & 72.04 & 4.35 & 32 & 114.68 & 6.23 & 72.40 & 3.48 \\
\hline 41-45 & 14 & 115.57 & 8.34 & 74.28 & 8.37 & 11 & 116.90 & 6.59 & 76.30 & 2.19 \\
\hline $46-50$ & 22 & 116.81 & 6.06 & 74.63 & 6.02 & 5 & 117.60 & 5.17 & 76.40 & 2.19 \\
\hline
\end{tabular}


Table 3:- Relationship between blood pressure status sex and height group.

\begin{tabular}{|c|c|c|c|c|c|c|c|c|c|c|}
\hline \multirow{3}{*}{$\begin{array}{l}\text { Weight } \\
\text { (Kgs) }\end{array}$} & \multicolumn{5}{|c|}{ Boys } & \multicolumn{5}{|c|}{ Girls } \\
\hline & \multirow[t]{2}{*}{ No: } & \multicolumn{2}{|c|}{ SBP (mmHg) } & \multicolumn{2}{|c|}{ DBP (mmHg) } & \multirow[t]{2}{*}{ No: } & \multicolumn{2}{|c|}{ SBP (mmHg) } & \multicolumn{2}{|c|}{ DBP (mmHg) } \\
\hline & & Mean & SD & Mean & SD & & Mean & SD & Mean & SD \\
\hline $91-100$ & 24 & 96.12 & 5.04 & 61.86 & 6.85 & 21 & 96.57 & 6.93 & 62.57 & 3.85 \\
\hline $101-110$ & 74 & 97.08 & 6.34 & 62.08 & 5.56 & 50 & 96.90 & 5.55 & 63.32 & 3.99 \\
\hline $111-120$ & 207 & 101.21 & 7.56 & 63.70 & 4.61 & 126 & 100.90 & 8.24 & 64.28 & 6.88 \\
\hline $121-130$ & 168 & 104.10 & 8.08 & 68.11 & 7.16 & 124 & 104.70 & 7.76 & 67.95 & 5.02 \\
\hline $131-140$ & 151 & 107.84 & 8.02 & 69.05 & 6.07 & 118 & 107.00 & 9.23 & 70.06 & 4.67 \\
\hline $141-150$ & 93 & 110.32 & 7.09 & 70.70 & 4.54 & 74 & 109.35 & 8.10 & 70.47 & 4.96 \\
\hline $151-160$ & 50 & 114.16 & 6.98 & 73.00 & 5.30 & 20 & 113.30 & 13.14 & 74.42 & 3.76 \\
\hline $161-170$ & 14 & 118.28 & 7.35 & 76.00 & 6.88 & 06 & 120.26 & 4.80 & 77.60 & 4.33 \\
\hline
\end{tabular}

Table 4:- Showing prevalence of hypertension as per fourth Report.

\begin{tabular}{|c|c|c|c|c|c|c|c|c|}
\hline \multirow{3}{*}{$\begin{array}{l}\text { Age } \\
\text { in } \\
\text { years }\end{array}$} & \multicolumn{4}{|c|}{ Boys } & \multicolumn{4}{|c|}{ Girls } \\
\hline & \multirow{2}{*}{$\begin{array}{l}\text { Total } \\
\text { No of } \\
\text { boys }\end{array}$} & \multirow{2}{*}{$\begin{array}{l}\text { cut off point } \\
\text { (95th percentile) } \\
\text { mmHg }\end{array}$} & \multicolumn{2}{|c|}{ Hypertensive } & \multirow{2}{*}{$\begin{array}{l}\text { Total } \\
\text { No of } \\
\text { girls }\end{array}$} & \multirow{2}{*}{$\begin{array}{l}\text { cut off point } \\
\text { (95 } 95^{\text {th }} \text { percentile) } \\
\text { mmHg }\end{array}$} & \multicolumn{2}{|c|}{ Hypertensive } \\
\hline & & & no & $\%$ & & & No & $\%$ \\
\hline 06 & 87 & $104 / 68$ & 2 & 2.29 & 53 & $104.8 / 68$ & 2 & 3.77 \\
\hline 07 & 79 & $107 / 70$ & 2 & 2.53 & 59 & $120 / 68.8$ & 2 & 3.38 \\
\hline 08 & 93 & $114 / 80$ & 2 & 2.15 & 40 & $110.3 / 72.9$ & 2 & 5 \\
\hline 09 & 81 & $118 / 80$ & 4 & 4.94 & 56 & $112 / 72.5$ & 1 & 1.78 \\
\hline 10 & 73 & $120 / 74.8$ & 2 & 2.73 & 70 & $119 / 80$ & 1 & 1.43 \\
\hline 11 & 74 & $120 / 78.7$ & 1 & 1.35 & 45 & $12 / 71.6$ & 1 & 2.22 \\
\hline 12 & 69 & $121.2 / 78.4$ & 1 & 1.45 & 59 & $120 / 74$ & 0 & 0 \\
\hline 13 & 66 & $118 / 73.5$ & 1 & 1.51 & 63 & $123.6 / 74$ & 1 & 1.58 \\
\hline 14 & 100 & $124.1 / 78$ & 2 & 2 & 46 & $118 / 76$ & 3 & 6.52 \\
\hline 15 & 59 & $122 / 78$ & 1 & 1.69 & 48 & $127.3 / 82.6$ & 1 & 2.08 \\
\hline Total & 781 & & 18 & 2.3 & 539 & & 14 & 2.4 \\
\hline
\end{tabular}

